Working Paper/Document de travail 2014-57

\title{
International Spillovers of Policy Uncertainty
}

by Stefan Klößner and Rodrigo Sekkel 
Bank of Canada Working Paper 2014-57

December 2014

\title{
International Spillovers of Policy Uncertainty
}

\author{
by
}

\author{
Stefan Klößner ${ }^{1}$ and Rodrigo Sekkel ${ }^{2}$ \\ 1Statistics and Econometrics \\ Saarland University \\ 66123 Saarbrücken, Germany \\ S.Kloessner@mx.uni-saarland.de \\ ${ }^{2}$ Canadian Economic Analysis Department \\ Bank of Canada \\ Ottawa, Ontario, Canada K1A 0G9 \\ Corresponding author: rsekkel@bankofcanada.ca
}

Bank of Canada working papers are theoretical or empirical works-in-progress on subjects in economics and finance. The views expressed in this paper are those of the authors. No responsibility for them should be attributed to the Bank of Canada. 


\section{Acknowledgements}

We thank Christiane Baumeister, André Binette, José Dorich, Soojin Jo, Glen Keenleyside, Tatevik Sekhposyan, an anonymous referee and seminar participants at the Bank of Canada for helpful comments. 


\begin{abstract}
Using the Baker et al. (2013) index of policy uncertainty for six developed countries, this paper estimates spillovers of policy uncertainty. We find that spillovers account for slightly more than one-fourth of the dynamics of policy uncertainty in these countries, with this share rising to one-half during the financial crisis. The United States and United Kingdom are responsible for a large fraction of the spillovers since the financial crisis, while Canada and the remaining countries are all net receivers of policy uncertainty shocks during and after this period.

JEL classification: C3, D80, F42

Bank classification: Econometric and statistical methods
\end{abstract}

\title{
Résumé
}

À l'aide de l'indice d'incertitude sur la politique économique établi par Baker et autres (2013), les auteurs estiment les retombées de l'incertitude au sujet de la politique économique dans le cas de six pays développés. Ils constatent que ces effets d'entraînement contribuent pour un peu plus du quart à la dynamique de l'incertitude sur la politique économique dans ces pays, proportion qui a grimpé à $50 \%$ durant la crise financière. Depuis cette dernière, une grande part des retombées de l'incertitude émanent des États-Unis et du Royaume-Uni. Quant au Canada et aux autres pays, ils ont surtout subi les chocs d'incertitude liés à la politique économique pendant et après cette période.

Classification JEL : C3, D80, F42

Classification de la Banque : Méthodes économétriques et statistiques 


\section{Introduction}

Since the start of the financial crisis and the subsequent Great Recession, there has been a renewed interest in the study of the impacts of uncertainty on economic activity. The highly influential paper by Bloom (2009) has sparked a series of papers examining the impact of various kinds of uncertainty on economic activity. ${ }^{1}$ Within this quickly expanding literature, a set of papers have examined the international transmission of uncertainty shocks. Mumtaz and Theodoridis (2012) investigate the transmission of U.S. GDP growth volatility shocks to the United Kingdom using a structural vector autoregressive (VAR) model with time-varying volatility. Related to this paper, Colombo (2013) studies the impact of United States and euro area policy uncertainty, as measured by Baker et al. (2013), on euro area economic activity. She finds that U.S. policy uncertainty shocks have a higher impact on euro area economic activity than euro area policy uncertainty itself. Finally, IMF (2013) studies how policy uncertainty shocks in the United States and euro area affect growth in other world regions.

In this paper, we depart from the previous literature and investigate the spillovers in policy uncertainty among a group of countries, with a focus on how policy uncertainty in one country influences uncertainty in the remaining ones. Are the dynamics of policy uncertainty in one country influenced by uncertainty shocks in other countries? What is the overall level of uncertainty spillovers among all countries in our sample? Are some countries net exporters/importers of uncertainty? To answer these questions, we use the Diebold and Yilmaz (2009); Diebold and Yllmaz (2014) spillover measures and policy uncertainty indices of Baker et al. (2013) for six developed countries (Canada, France, Germany, Italy, United Kingdom and United States) in order to calculate a policy uncertainty spillover index (SOI). The SOI is based on standard variance decompositions in vector autoregressions, which allows us to calculate pairwise directional spillovers and to aggregate them further into a consistent single measure.

Recent events offer us many examples of how policy uncertainty might spill over across countries. Following the financial crisis, the Federal Reserve implemented a series of unconventional monetary policy actions that increased the size of the Federal Reserve balance sheets to levels never seen before. Faced with a significant decline in gross domestic product, the

\footnotetext{
${ }^{1}$ See, among others, Baker et al. (2013); Jurado et al. (2013); Leduc and Liu (2012); Bijsterbosch and Guérin (2013); Caggiano et al. (2014).
} 
U.S. federal government engaged in a large expansionary fiscal stimulus. These actions had important effects on capital flows, bond risk premia, and exchange rates, for example, with the potential effect of increasing policy uncertainty in other economies faced with a choice of how to react to these developments. At the same time, these economies were also hit by a negative financial shock and undertook policy actions of their own, with potential feedbacks to U.S. policy uncertainty. It is important to note, however, that as in Diebold and Yilmaz (2009), we do not attach a causal interpretation to the word spillover, since we are unable to identify structural channels. Rather, the aim of the SOI is simply to highlight the overall and pairwise directional connectedness among all countries in the sample.

We find a high degree of policy uncertainty spillovers. For most countries, around 35\% of the volatility of their policy uncertainty shocks can be explained by shocks originating in other countries. Moreover, we find that policy uncertainty spillovers are highly countercyclical, having risen sharply during the last financial crisis. We are also able to show which countries are transmitting uncertainty shocks, as well as receiving them the most. We show that since the financial crisis and Great Recession, the United Kingdom and particularly the United States have been strong net exporters of policy uncertainty shocks, while the remaining countries have been net importers of policy uncertainty shocks.

This paper proceeds as follow. First, we describe the methodology for calculating spillovers. Section 3 describes the data set. We then follow with the results, and finally, section 5 concludes.

\section{Methodology}

We use the methodology for construction of spillover measures suggested by Diebold and Yilmaz (2009), with an algorithm created by Klößner and Wagner (2014) to calculate robust spillover measures.

Consider an N-dimensional $\operatorname{VAR}(\mathrm{p})$ model, $Y_{t}=\Phi_{1} Y_{t-1}+\ldots+\Phi_{p} Y_{t-p}+\epsilon_{t}$, where $\epsilon_{t}$ is an independent and identically distributed shock. The coefficient matrices $\Phi_{1}, \ldots, \Phi_{p}$ summarize all the dynamic relationships among the variables. By stationarity, the system above has a moving-average representation $Y_{t}=\epsilon_{t}+A_{1} \epsilon_{t-1}+A_{2} \epsilon_{t-2}+\ldots$ Let $P\left(Y_{t+H} \mid Y_{t}, Y_{t-1}, \ldots\right)$ be the $H$-step-ahead forecast at time $t$. Diebold and Yilmaz (2009) summarize the information contained in the coefficient matrices in spillover measures with $H$-step-ahead forecast-error 
variance decompositions

$$
Y_{t+H}-P\left(Y_{t+H} \mid Y_{t}, Y_{t-1}, \ldots\right)=\epsilon_{t+H}+A_{1} \epsilon_{t+H-1}+A_{2} \epsilon_{t+H-2}+\ldots+A_{H-1} \epsilon_{t+1}
$$

Letting $\Sigma_{\epsilon}$ be the covariance matrix of $\epsilon$, and $A_{0}:=I_{N}$, the forecast error's covariance matrix is given by $\Sigma_{\epsilon, H}=\sum_{h=0}^{H-1} A_{h} \Sigma_{\epsilon} A_{h}^{\prime}$.

Following Diebold and Yilmaz (2009), we use the lower-triangular Cholesky factor L of the $\Sigma_{\epsilon}$ matrix (i.e., the lower-triangular matrix L such that $L L^{\prime}=\Sigma_{\epsilon}$ ). Using $L, A_{h} \Sigma_{\epsilon} A_{h}^{\prime}$ can be written as $\left(A_{h} L\right)\left(A_{h} L\right)^{\prime}$, and hence $\left(A_{h} \Sigma_{\epsilon} A_{h}^{\prime}\right)_{i i}=\sum_{j=1}^{N}\left(A_{h} L\right)_{i j}^{2}$ for variable $i$ 's forecast-error variance. Thus, $\sum_{h=0}^{H-1}\left(A_{h} L\right)_{i j}^{2}$ can be considered as the contribution of shocks to variable $j$ to variable $i$ 's forecast-error variance. Diebold and Yilmaz (2009) summarize all the information on the various spillovers into a single number, a spillover index (SOI):

$$
S O I:=100 \times \frac{1}{N} \sum_{i=1}^{N} \frac{\sum_{i \neq j} \sum_{h=0}^{H-1}\left(A_{h} L\right)_{i j}^{2}}{\sum_{h=0}^{H-1}\left(A_{h} \Sigma_{\epsilon} A_{h}^{\prime}\right)_{i i}}=100 \times\left(1-\frac{1}{N} \sum_{i=1}^{N} \frac{\sum_{h=0}^{H-1}\left(A_{h} L\right)_{i i}^{2}}{\sum_{h=0}^{H-1}\left(A_{h} \Sigma_{\epsilon} A_{h}^{\prime}\right)_{i i}}\right) .
$$

The spillover index is invariant to rescaling of the variables. Assuming that all variables have been scaled such that their respective forecast errors are equal to unity, one can replace (1) with the following more straightforward formula:

$$
S O I=100 \times\left(1-\frac{1}{N} \operatorname{tr}\left(\sum_{h=0}^{H-1}\left(A_{h} L\right)^{2}\right)\right)
$$

with the operator (.) 2 which squares a matrix elementwise.

As is widely known, the Cholesky decomposition is not invariant to the ordering of the $\Sigma_{\epsilon}$ matrix. Different orderings may thus result in significantly different spillover estimates, as shown by Klößner and Wagner (2014). We therefore apply their proposed algorithm to conveniently calculate robust spillover measures by averaging the results over all possible permutations of the system. ${ }^{2}$ We refer the reader to their paper for a detailed exposition of their algorithm.

\footnotetext{
${ }^{2}$ With six countries in our sample, we have 720 different orderings.
} 


\section{Data}

The policy uncertainty measures are readily available at the policy uncertainty website. ${ }^{3}$ Our sample is monthly, for the period January 1997 to September 2013, and comprises the following countries: Canada, France, Germany, Italy, the United Kingdom and the United States. The indices are based on a weighted average of a news-based measure of uncertainty and forecast disagreement among professional forecasters. For a more detailed explanation of how the index was constructed for each country, we refer the reader to Baker et al. (2013), and their policy uncertainty website.

Figure 1 plots the data and Table 1 presents the correlation matrix for the policy uncertainty indices in the various countries. The highest pairwise correlation is between the United States and the United Kingdom, at 83\%. Italy has the smallest average pairwise correlation with the other countries. The figure indicates a significant co-movement among policy uncertainty measures in the different countries. For all countries in the sample, though to varying degrees, there is a rise in uncertainty around 2001, possibly following the bursting of the dot-com bubble in the United States, as well as the subsequent recession. The next notable spikes are the 2008 financial crisis, the Great Recession, as well as a significant spike at the end of 2012. For all countries in our sample, policy uncertainty is significantly higher and more volatile after the financial crisis than in the beginning of the sample.

\section{Results}

In order to calculate the spillover indices, one has to specify a lag structure for the VAR, as well as choose a forecast horizon for the forecast-error decomposition. Our baseline results are for a $\operatorname{VAR}(2)$, and $H=3$. In a robustness appendix, we show results for different lag orders and forecast horizons. The longer the horizon, the less important the conditional information in the VAR. We show the results for the average spillover index. Additional results with different VAR lag lengths, as well as different forecast horizons, are available upon request.

\footnotetext{
${ }^{3}$ http://www.policyuncertainty.org
} 


\subsection{Full-Sample Analysis}

We start by providing a full-sample analysis of policy uncertainty spillovers from January 1997 to September 2013. We provide estimates of the overall SOI, as well as all the forecasterror variance components for country $i$ coming from country $j$, for all $i$ and $j$. Table 2 summarizes the results. It shows the average variance - across all permutations of the system - of the forecast error that each country transmits to (column) and receives from (rows) all other countries. It also shows the total variance of the forecast errors that each country sends to all other countries (the row To Others), as well as the fraction of the forecast error each country receives from all other countries (the column From Others). Finally, it also contains the total SOI.

The spillover index for the full sample is 27.11 , meaning that slightly more than one-fourth of the total variance of the forecast errors for the six countries in our sample is explained by spillovers of shocks across countries, and thus roughly three-fourths of this variance is then explained by idiosyncratic country-specific shocks.

The United States, followed by the United Kingdom, contributed the most to the variance of the forecast errors of the remaining countries, as shown by the To Others row in Table 2 . Both countries are also the biggest net exporters of uncertainty shocks (To Others - From Others). On the other hand, Canada, Germany and Italy are all net importers of uncertainty shocks. Italy is the most isolated country in the sample, with most of its policy uncertainty being driven by their own domestic shocks. It also explains little of the variance of the forecast errors of the other countries.

\subsection{Rolling-Sample Analysis}

Section 4.1 discussed the full-sample spillover results. There were clearly many changes throughout our sample, most noticeably the financial crisis and the subsequent Great Recession. It is, then, highly questionable that fixed parameter models should apply for the whole sample. Thus, in this section, we estimate the overall spillover index, as well as the total directional spillovers to and from the individual countries, using a rolling window of 60 months starting in January 1997.

Figure 2 shows the dynamics of the spillover index from January 2002 to September 2013. As expected, there is important time variation in the estimates of the SOI. From 2002 to 
about mid-2006, the SOI was relatively high, following the bursting of the dot-com bubble and the September 2001 terrorist attacks. It then fell to its lowest level at the beginning of 2008, only to experience a significant and fast increase during the global financial crisis. Even though the policy uncertainty indices for all countries in the sample have remained very high from 2009 onwards, their variations were caused, for example, by events such as the U.S. debt ceiling crisis and government shutdown, and various crises in European countries. Therefore, the policy uncertainty shocks seemed to have been rather idiosyncratic, resulting in a falling SOI. This analysis corroborates the conjecture that there were important spillovers in policy uncertainty during the financial crisis. Therefore, not only is policy uncertainty highly countercyclical, as previously shown by Bloom (2009), but the overall connectedness in policy uncertainty among countries is also strongly countercyclical.

In addition to the total SOI, it is also interesting to examine the time variation in the total spillovers to and from each country, as shown in Figure 3. It is evident that there is substantial time variation in the spillovers throughout our sample. The most dramatic change seems to be associated with the financial crisis, when there was a dramatic increase for all other countries in the share of forecast-error variance due to policy uncertainty shocks in the United States. At the same time, the share of U.S. forecast-error variance due to shocks in the remaining countries did not increase, making the United States a significant net exporter of uncertainty during this period. Finally, it is interesting to note that Germany has been a net receiver of policy uncertainty throughout the whole sample, especially during the financial crisis and the following recession.

\section{Conclusions}

This paper estimated the spillovers of policy uncertainty among six developed countries. We find that spillovers account for a share of slightly more than one-fourth of the dynamics of policy uncertainty, with this share rising to one-half during the financial crisis period. The United States and United Kingdom are responsible for a large fraction of the spillovers since

the financial crisis, while Canada and the remaining countries are all net receivers of policy uncertainty shocks during and after this period. 


\section{References}

Baker, S., N. Bloom, And S. DAVis (2013): "Measuring economic policy uncertainty," Chicago Booth Research Paper.

Bijsterbosch, M. AND P. GuÉRin (2013): "Characterizing very high uncertainty episodes," Economics Letters, 121, 239-243.

Bloom, N. (2009): "The impact of uncertainty shocks," Econometrica, 77, 623-685.

Caggiano, G., E. Castelnuovo, and N. Groshenny (2014): "Uncertainty Shocks and Unemployment Dynamics in US Recessions," Melbourne Institute Working Paper No.12/14.

Colombo, V. (2013): "Economic policy uncertainty in the US: Does it matter for the Euro area?" Economics Letters, 121, 39-42.

Diebold, F. X. And K. Yilmaz (2009): "Measuring Financial Asset Return and Volatility Spillovers, with Application to Global Equity Markets*," The Economic Journal, 119, $158-171$.

Diebold, F. X. And K. Yilmaz (2014): "On the network topology of variance decompositions: Measuring the connectedness of financial firms," Journal of Econometrics.

IMF (2013): “2013 Spillover Report: Analytical Underpinnings and other Background,” IMF Spillover Report.

Jurado, K., S. C. Ludvigson, And S. NG (2013): "Measuring Uncertainty," New York University, mimeo.

KLÖssner, S. And S. Wagner (2014): "Exploring All VAR Orderings for Calculating Spillovers? Yes, We Can! A Note on Diebold and Yilmaz (2009)," Journal of Applied Econometrics, 29, 172-179.

LEDUC, S. AND Z. LiU (2012): "Uncertainty shocks are aggregate demand shocks," Federal Reserve Bank of San Francisco Working Paper.

Mumtaz, H. AND K. Theodoridis (2012): "The international transmission of volatility shocks: an empirical analysis," Bank of England Working Paper No. 463. 
Table 1: Correlation Matrix

\begin{tabular}{ccccccc}
\hline & Canada & France & Germany & Italy & US & UK \\
Canada & 1.00 & & & & & \\
France & 0.63 & 1.00 & & & & \\
Germany & 0.71 & 0.66 & 1.00 & & & \\
Italy & 0.60 & 0.48 & 0.42 & 1.00 & & \\
US & 0.79 & 0.79 & 0.72 & 0.58 & 1.00 & \\
UK & 0.78 & 0.77 & 0.76 & 0.55 & 0.83 & 1.00 \\
\hline \hline
\end{tabular}

Note: This table shows the correlation matrix among all policy uncertainty indices between January 1997 and September 2013.

Table 2: Spillover Table

\begin{tabular}{cccccccc}
\hline & U.S. & Canada & France & Germany & Italy & UK & From Others \\
U.S. & 66.75 & 9.35 & 7.56 & 5.01 & 1.51 & 9.81 & 33.24 \\
Canada & 13.51 & 65.42 & 2.82 & 5.86 & 1.30 & 11.08 & 34.57 \\
France & 4.95 & 2.00 & 79.49 & 3.04 & 1.61 & 8.91 & 20.51 \\
Germany & 14.24 & 7.56 & 3.91 & 65.28 & 1.72 & 7.28 & 34.71 \\
Italy & 3.93 & 3.07 & 2.39 & 2.00 & 87.26 & 1.36 & 12.75 \\
UK & 9.14 & 6.12 & 6.97 & 3.65 & 1.01 & 73.12 & 26.89 \\
\hline To Others & 45.77 & 28.10 & 23.65 & 19.56 & 7.15 & 38.44 & \\
\hline Net & 12.53 & -6.47 & 3.14 & -15.15 & -5.60 & 11.55 & SOI=27.11 \\
\hline \hline
\end{tabular}

Notes: This table shows the Robust Spillover Table for the period January 1997 to September 2013. It is based on the average across all $N !=720$ permutations of the system. The columns show the fraction of the forecast-error variance that the headline country exports to all countries. The rows indicate the fraction of the forecast-error variance that the headline country imports from all countries. The row Net displays the difference between To Others and From Others. The SOI, the average of all non-diagonal entries, equals 27.11. 
Figure 1: Policy Uncertainty Indices

\section{Canada}

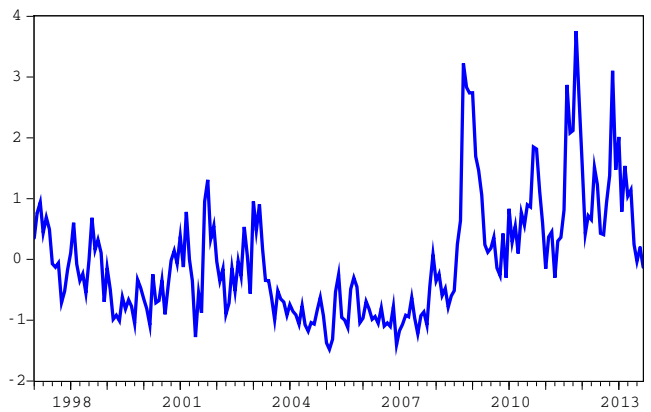

Germany

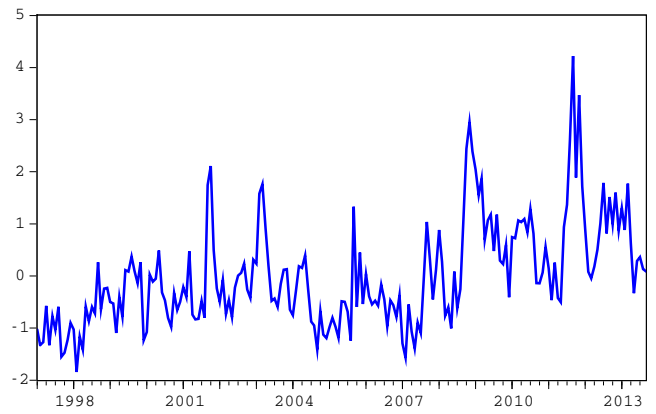

United Kingdom

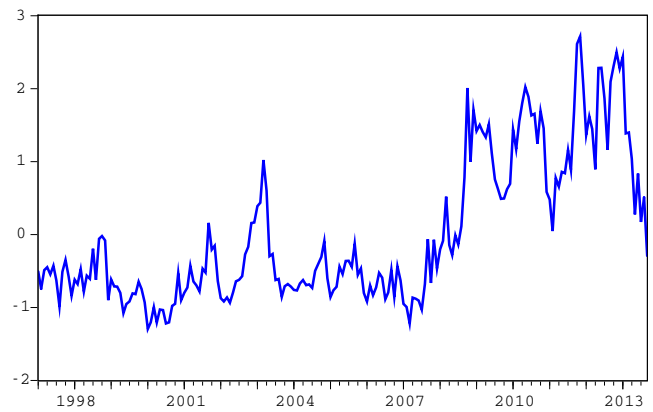

France

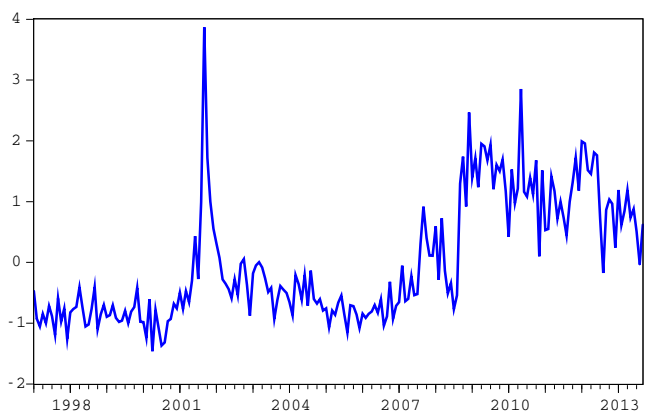

Italy

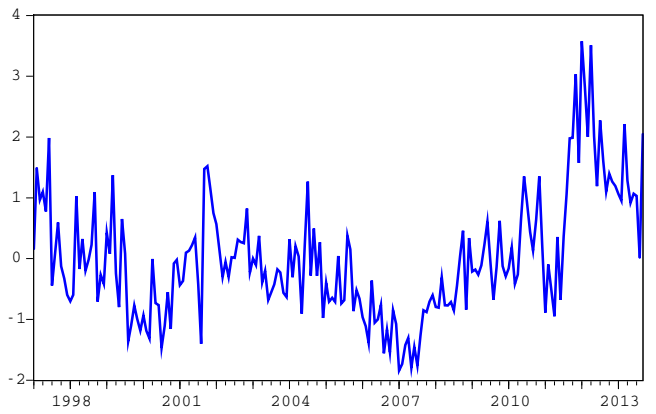

United States

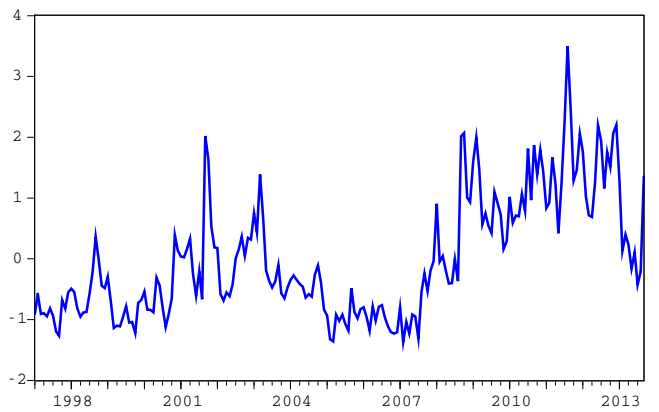

Notes: This figure shows the standardized spillover indices for the six countries in our sample. The sample starts in January 1997 and ends in September 2013. 


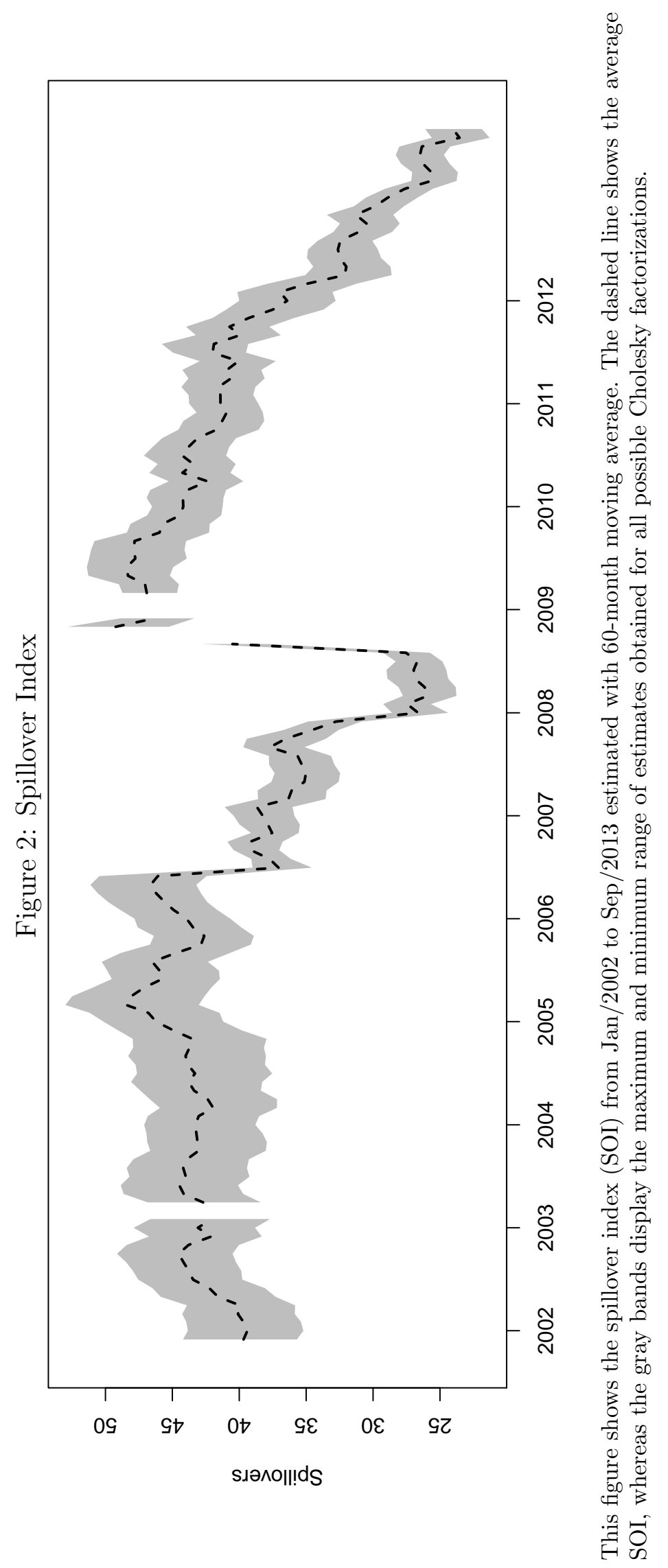


Figure 3: Total From and Total To Dynamic Spillovers
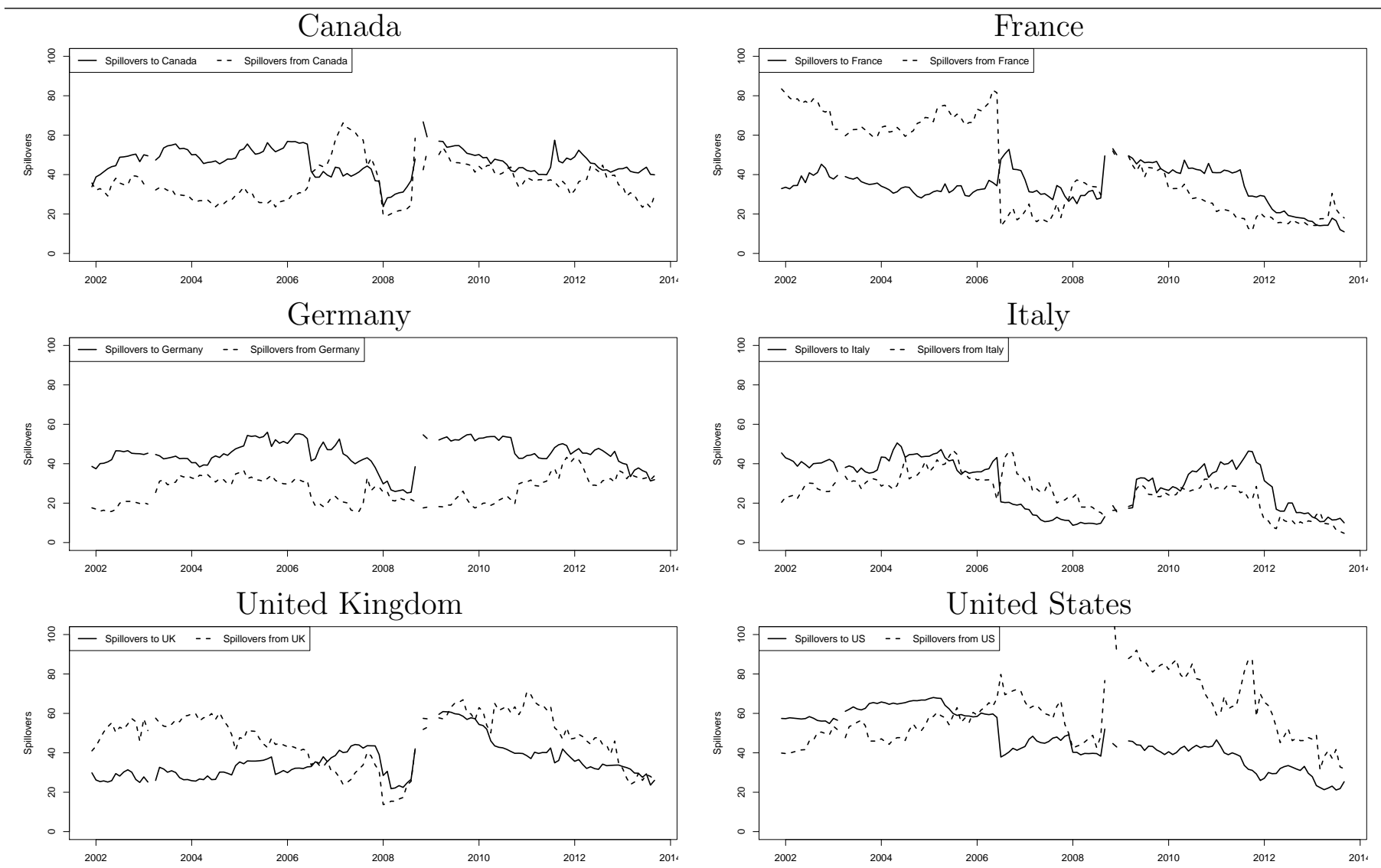

Notes: This figure shows the average Total From and Total To dynamic spillovers for all countries averaged over all possible permutations of the system, and estimated with a rolling window of 60 months. The difference between the two lines represents the net spillovers. Positive net spillovers means the country in question is a net exporter of uncertainty, whereas a negative gap means the country is a net importer of uncertainty. 